\title{
Reconnection-Less Electronically Reconfigurable Filter with Adjustable Gain Using Voltage Differencing Current Conveyor
}

\author{
Jan Jerabek ${ }^{1}$, Roman Sotner ${ }^{2}$, Josef Polak ${ }^{1}$, Kamil Vrba ${ }^{1}$, Tomas Dostal ${ }^{3}$ \\ ${ }^{1}$ Department of Telecommunications, Faculty of Electrical Engineering and Communication, \\ Brno University of Technology, \\ Technicka 12, Brno, 616 00, Czech Republic \\ ${ }^{2}$ Department of Radio Electronics, Faculty of Electrical Engineering and Communication, \\ Brno University of Technology \\ Technicka 12, Brno, 616 00, Czech Republic \\ ${ }^{3}$ Department of Technical Studies, College of Polytechnics Jihlava, \\ Tolsteho 16, Jihlava 586 01, Czech Republic \\ jerabekj@feec.vutbr.cz
}

\begin{abstract}
This paper presents a novel reconnection-less and electronically reconfigurable analogue filter. It employs two active elements, Voltage-Differencing Current Conveyor (VDCC) and Dual-Output Current Amplifier (DO-CA) with two independently tunable gains. Filter has the single input and single output topology (SISO). The current-mode transfer function of the filter can be tuned electronically from the lowpass (LP) response to the high-pass (HP) response, via the band-stop (BS) response, without reconnection of the input or output terminal. It is designed in order to provide tuning of both the stop-band gain and also pass-band gain of all the transfer functions, because also transfer functions with additional and intended zero in transfer function are available. The theoretical presumptions are confirmed by both simulations and lab measurements with available devices.
\end{abstract}

Index Terms-Dual-output current amplifier; DO-CA; reconfigurable filter; reconnection-less filter; voltage differencing current conveyor; VDCC.

\section{INTRODUCTION}

\section{A. Reconfigurability of the Transfer Function}

Possibility of modification or fine adjusting of the transfer function of an analogue circuit is always a very important requirement in the signal processing domain [1]. Reconfigurability is a very useful feature of the analogue filters since it represents the possibility of very fast change of the type of the frequency response. However, manual galvanic reconnection is usually necessary in order to change the type of the transfer response in standard multifunctional solutions. Unfortunately, manual reconnection is not possible or easily accessible in many cases (e.g. in case of on-chip implementation). Many recent scientific works [2]-

Manuscript received 10 October, 2015; accepted 11 May, 2016.

Research described in this paper was financed by the National Sustainability Program under grant LO1401 and by the Czech Science Foundation under grant no. 14-24186P. For the research, infrastructure of the SIX Center was used.
[7] solve the problem by the filters referred to as multifunction. These filters have several transfer functions available, but between different nodes of the network. These circuits are referred to as a single input - multiple output (SIMO) [8] or a multiple input - single output (MISO) [9]. Required change of the filtering function can be realized also by switches - this concept is similar to the SIMO and MISO circuits. However, switching of inputs or outputs is not very favourable and causes additional problems (power consumption, overshoots, interferences of clock signal to analogue path, and area consumption on chip). Additionally, some effects caused by discontinuous regime of switching are undesired. Therefore, a very interesting concept is to use two-port structure without changing internal topology or a position of input or output port, used also in microwave technique, for instance [10]. These circuits are referred to as single input - single output (SISO). Our paper focuses on the filtering solution that allows reconnection-less and switch-less control of the type of the transfer function electronically by the parameter(s) of advanced active element and also tuning of the stop-band and/or pass-band attenuation.

Many papers present the filters referred to as reconfigurable [11], [12] but in point-of-view of adjustability of bandwidth or quality factor (in the case of band-pass response). From our point of view, reconfigurable filter [13], [14] represents the type of transfer function where reconfigurability is available without any reconnection in the structure.

\section{B. Active Elements}

Many advanced active elements have been reported in recent works. A detailed summarization is available in [15]. However only active elements with the electronically adjustable parameter(s) are interesting for purposes of reconfigurable filters. We focus our attention on adjustable current amplifiers [15]-[17], operational transconductance 
amplifiers (OTAs) [15], [18] and current conveyors (CC) [15], [19] because of their useful features, wide availability and easy mutual interconnection.

Several other active elements were derived from these fundamental active elements, usually by complementing two active elements into one structure with particular features. The typical examples are numerous modifications of the current differencing transconductance amplifier (CDTA) [15], [20]-[22]. Several more complex active elements, based on OTA section and $\mathrm{CC}$ of the second generation (CCII) have been also proposed. For example, current conveyor transconductance amplifier (CCTA) [15]-[23] utilizes independent $R_{\mathrm{x}}$ and $g_{\mathrm{m}}$ control in some of its variants [24]. Modification of CCTA in [10] employs current gain control. Controllable current gain in frame of CCII seems to be a valuable advantage [25], [26]. This active element is usually referred to as ECCII (Current Conveyor of the second generation with electronically adjustable gain between $\mathrm{X}$ and $\mathrm{Z}$ terminal). Another interesting active element is Voltage Differencing Current Conveyor (VDCC) [15], [27]-[29]. Also simple current followers (CF) and voltage buffers $(\mathrm{VB})$ or their variations are useful.

\section{Comparison with other SISO Solutions in Literature}

Several solutions of reconnection-less and reconfigurable filters of SISO type have been published in open literature [30]-[38]. $1^{\text {st }}$-order filters are summarized in Table I, 2ndorder filters in Table II. Note that the solution presented in this paper is of the $2^{\text {nd }}$ order and therefore it is included in Table II in order to provide a comparison.

\section{TABLE I. 1ST-ORDER RECONNECTION-LESS FILTERS OF SISO TYPE WITH RECONFIGURATION.}

\begin{tabular}{|c|c|c|c|c|c|c|}
\hline 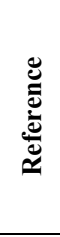 & 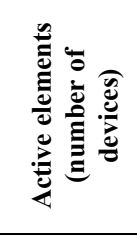 & 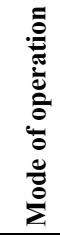 & 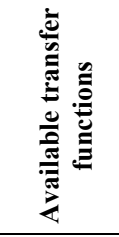 & 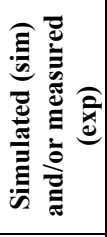 & 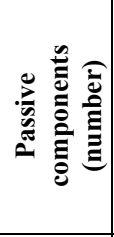 & 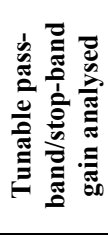 \\
\hline [30] & $\begin{array}{l}\text { ZC-CG- } \\
\text { VDCC (1) }\end{array}$ & VM & $\begin{array}{c}\mathrm{HP}, \mathrm{iAP}, \\
\text { DT }\end{array}$ & $\begin{array}{c}\operatorname{sim} \& \\
\exp \end{array}$ & C (1) & no/no \\
\hline [31] & $\begin{array}{l}\text { OTA (2), } \\
\text { ECCII (1) }\end{array}$ & VM & $\begin{array}{c}\text { AP, LPZ, } \\
\text { iDT, AZ }\end{array}$ & sim & C (1) & no/no \\
\hline [32] & OTA (2) & VM & $\begin{array}{c}\mathrm{AP}, \mathrm{HP} \\
\mathrm{LP}\end{array}$ & $\operatorname{sim}$ & $\begin{array}{c}\mathrm{C}(1), \mathrm{R} \\
(1)\end{array}$ & no/no \\
\hline [33] & MCDU (1) & $\mathrm{CM}$ & $\begin{array}{l}\mathrm{AP}, \mathrm{iHP} \\
\mathrm{LP}\end{array}$ & $\begin{array}{c}\operatorname{sim} \& \\
\exp \end{array}$ & C (1) & no/no \\
\hline [34] & MCDU (1) & $\mathrm{CM}$ & $\begin{array}{c}\text { HP, LP, } \\
\text { AP }\end{array}$ & $\operatorname{sim}$ & C (1) & no/no \\
\hline
\end{tabular}

TABLE II. 2ND-ORDER RECONNECTION-LESS FILTERS OF SISO TYPE WITH RECONFIGURATION.

\begin{tabular}{|c|c|c|c|c|c|c|}
\hline 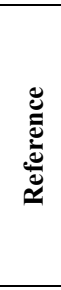 & 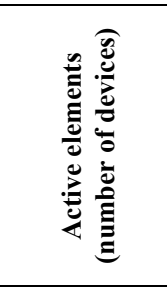 & 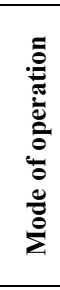 & 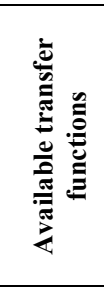 & 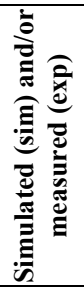 & 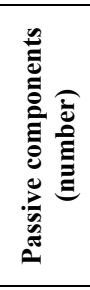 & 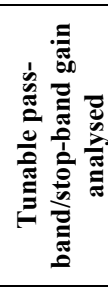 \\
\hline [35] & $\begin{array}{c}\text { ECCII (1), } \\
\text { VB (1) }\end{array}$ & VM & AP, BP & sim & C (2) & no/yes \\
\hline [36] & $\begin{array}{c}\text { OTA (5), VB } \\
\text { (1) }\end{array}$ & VM & $\mathrm{AP}, \mathrm{BS}$ & $\operatorname{sim}$ & $\begin{array}{l}\mathrm{C}(2) \\
\mathrm{R}(1)\end{array}$ & no/no \\
\hline
\end{tabular}

\begin{tabular}{|c|c|c|c|c|c|c|}
\hline [37] & OTA (4) & VM & $\begin{array}{c}\text { AP, iBP, } \\
\text { BS, LPZ, } \\
\text { HPZ }\end{array}$ & $\operatorname{sim}$ & C (2) & no/yes \\
\hline [38] & OTA (4) & VM & $\begin{array}{c}\text { AP, BS, } \\
\text { HP, iBP, } \\
\text { HPZ, LPZ }\end{array}$ & $\begin{array}{c}\operatorname{sim} \& \\
\exp \end{array}$ & C (2) & no/yes \\
\hline Fig. 4 & $\begin{array}{c}\text { VDCC (1), } \\
\text { CA (1) }\end{array}$ & CM & $\begin{array}{c}\text { LP, HP, } \\
\text { LPZ, HPZ, } \\
\text { BS }\end{array}$ & $\begin{array}{c}\operatorname{sim} \& \\
\exp \end{array}$ & $\begin{array}{c}\mathrm{C}(2), \\
\text { R (1) }\end{array}$ & yes/yes \\
\hline
\end{tabular}

Note: list of previously unexplained abbreviations used in Table I and Table II: ZC-CCCFDITA - Z-copy Current-Controlled Current Follower Differential Input Transconductance Amplifier

ECCII - Current Conveyor of the second generation with electronically adjustable gain between $X$ and $Z$ terminal

$M C D U$ - Modified Current Differencing Unit

VDCC - Voltage Differencing Current Conveyor

VM, CM - Voltage mode, Current Mode

$A P$, iAP - (inverting) all-pass filter

$H P$, iHP, HPZ - (inverting) high-pass filter (with zero)

$D T, i D T$ - (inverting) direct transfer

$L P, i L P, L P Z$ - (inverting) low-pass filter (with zero)

$A Z$ - adjustable zero

$B P, i B P$ - (inverting) band-pass filter

$B S, i B S$ - (inverting) band-stop filter

Our solution consists of only two active elements (it is not so common), operates in the current mode (none of already published 2nd-order filters) and it provides LP, HP, LPZ, HPZ and BS functions. Its features were verified also by lab measurement. Note that its pass-band gain is tunable independently of the stop-band gain. None of the previously reported filters provides this combination of the features.

\section{Definition of Active Elements}

The Dual Output Current Amplifier (DO-CA) with two independent gains is the first active element with schematic symbol depicted in Fig. 1, together with a description of internal topology. Behaviour of DO-CA is as follows

$$
\left[\begin{array}{c}
v_{I N} \\
i_{B 1} \\
i_{B 2}
\end{array}\right]=\left[\begin{array}{ccc}
0 & 0 & 0 \\
B_{1} & 0 & 0 \\
B_{2} & 0 & 0
\end{array}\right] \times\left[\begin{array}{c}
i_{I N} \\
v_{B 1} \\
v_{B 2}
\end{array}\right] .
$$

Direction of all voltages and currents and meaning of variables from (1) is obvious from Fig. 1.

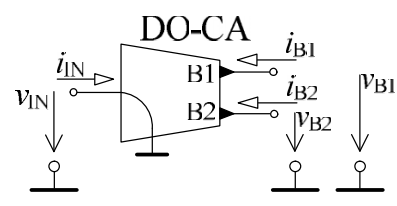

a)

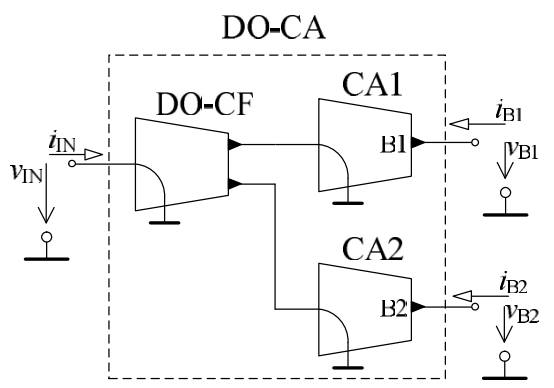

b)

Fig. 1. Dual Output Current Amplifier (DO-CA) with two independent gains: (a) - schematic symbol, (b) - internal topology. 


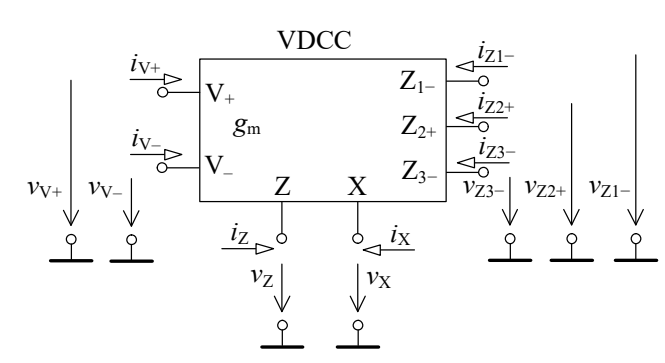

a)

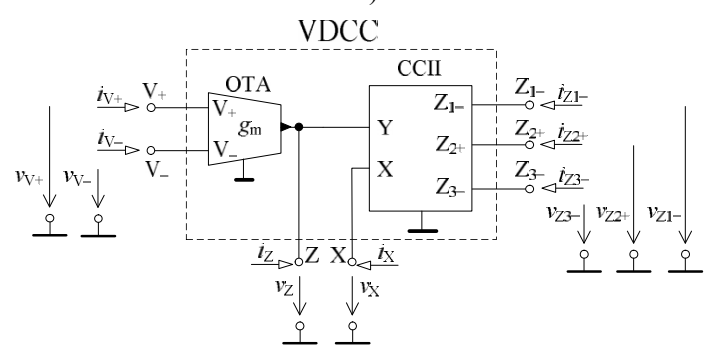

b)

Fig. 2. Voltage Differencing Current Conveyor (VDCC): (a) - schematic symbol, (b) - internal topology.

The Voltage Differencing Current Conveyor (VDCC) is the second type of active element that is present in the designed filter. It is well-known active element consisting of OTA and CCII as is obvious from Fig. 2.

All voltages, currents and variables from Fig. 2 are again included in the matrix

$$
\left[\begin{array}{c}
I_{V+} \\
I_{V-} \\
I_{Z} \\
V_{X} \\
I_{Z 1-} \\
I_{Z 2+} \\
I_{Z 3-}
\end{array}\right]=\left[\begin{array}{ccccccc}
0 & 0 & 0 & 0 & 0 & 0 & 0 \\
0 & 0 & 0 & 0 & 0 & 0 & 0 \\
-g_{m} & g_{m} & 0 & 0 & 0 & 0 & 0 \\
0 & 0 & 1 & 0 & 0 & 0 & 0 \\
0 & 0 & 0 & -1 & 0 & 0 & 0 \\
0 & 0 & 0 & 1 & 0 & 0 & 0 \\
0 & 0 & 0 & -1 & 0 & 0 & 0
\end{array}\right] \times\left[\begin{array}{c}
V_{+} \\
V_{-} \\
V_{Z} \\
I_{X} \\
V_{Z 1-} \\
V_{Z 2+} \\
V_{Z 3-}
\end{array}\right] .
$$

\section{DESIGNED RECONNECTION-LESS RECONFIGURABLE FILTER}

The designed reconnection-less reconfigurable filter of the SISO type is depicted in Fig. 3. It consists only of two active elements, two capacitors and one resistor.

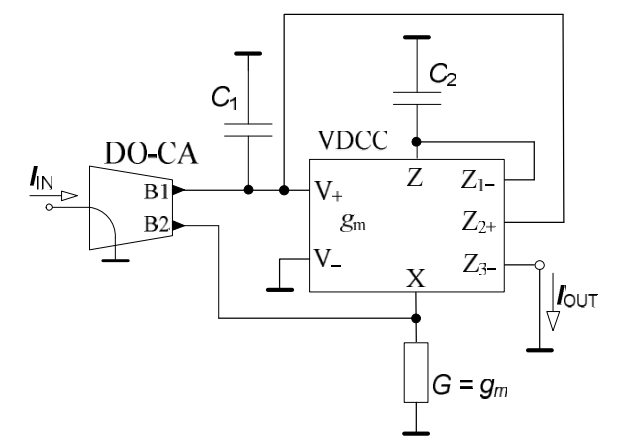

Fig. 3. Designed reconnection-less reconfigurable filter of the SISO type.

Ideal transfer function of the filter is

$$
K(\boldsymbol{s})=\frac{\boldsymbol{I}_{O U T}}{\boldsymbol{I}_{I N}}=\frac{\boldsymbol{s}^{2} C_{1} C_{2} B_{2}+G g_{m} B_{1}}{D(\boldsymbol{s})},
$$

where

$$
D(s)=s^{2} C_{1} C_{2}+s C_{1} G+g_{m} G
$$

From (3) and (4) it is obvious that pole frequency and quality factor are described by:

$$
\begin{gathered}
f_{P}=\frac{1}{2 \pi} \sqrt{\frac{g_{m} G}{C_{1} C_{2}}}, \\
Q=\sqrt{\frac{g_{m} C_{2}}{C_{1} G}} .
\end{gathered}
$$

The following transfer functions are obtained by controlling of adjustable current gains $\left(B_{1}, B_{2}\right)$ :

1. LP response, if $B_{2}=0$ and $B_{1} \neq 0$. Pass-band gain of the filter is adjusted by $B_{1}$. If $B_{1}>0\left(B_{1}<0\right)$, non-inverting (inverting) LP response is obtained and pass-band gain is directly proportional to $B_{1}$. If $\left|B_{1}\right|=1$, unity gain in lowfrequency pass band is achieved.

2. HP response, if $B_{1}=0$ and $B_{2} \neq 0$. Pass-band gain of the filter is adjusted by $B_{2}$. If $B_{2}>0\left(B_{2}<0\right)$, non-inverting (inverting) HP response is obtained and pass-band gain is directly proportional to $B_{2}$. If $\left|B_{2}\right|=1$, unity gain in highfrequency pass band is achieved.

3. BS response, if $B_{1}=B_{2} \neq 0$. Pass-band gain of the filter is adjusted by $B_{1}=B_{2}$. If $B_{1}=B_{2}>0\left(B_{1}=B_{2}<0\right)$, noninverting (inverting) BS response is obtained and passband gain is directly proportional to $B_{1}=B_{2}$. If $\left|B_{1}=B_{2}\right|$ $=1$, unity gain in both pass bands is achieved.

4. LPZ response, if $B_{1}>B_{2}>0$ or $B_{1}<B_{2}<0$. Also in this case, pass-band gain of the filter is adjusted by $B_{1}$, stopband gain is dependent on $B_{2}$. Other features are similar to LP response.

5. HPZ response, if $B_{2}>B_{1}>0$ or $B_{2}<B_{1}<0$. Also in this case, pass-band gain of the filter is adjusted by $B_{2}$, stopband gain is dependent on $B_{1}$. Other features are similar to HP response.

Note that $B_{2}<0$ and/or $B_{1}<0$ can be obtained with help of current mode multiplier, but this concept was not used in this paper. Moreover, if $g_{\mathrm{m}}=G$ is varied, pole frequency is controlled without disturbing quality factor value $(Q)$. Note that if only one additional current amplifier (with gain equal to $B_{3}$ ) is connected between $Z_{1}$ - and node with $C_{2}$ capacitor, $Q$ can be also controlled independently with respect to the pole frequency as obvious from the following equation. Denominator (3) changes to

$$
D^{\prime}(\boldsymbol{s})=g_{m} G+s C_{1} B_{3} G+s^{2} C_{1} C_{2} .
$$

\section{NON-IDEAL AND SENSITIVITY ANALYSIS}

When non-idealities of VDCC and DO-CA are taken into account, (4) changes to

$$
D(\boldsymbol{s})=-g_{m} G n_{11}+\boldsymbol{s} C_{1} G n_{12}+\boldsymbol{s}^{2} C_{1} C_{2},
$$

where $n_{11}$ represents non-ideal current transfer from $X$ terminal to $Z_{1}$ - (theoretically equal to -1 ) and $n_{12}$ represents 
non-ideal current transfer from $X$ terminal to $Z_{2+}$ (theoretically equal to 1 ). It is an easy task to calculate nonideal $f_{\mathrm{p}}$ and $Q$ from (8) (therefore it is omitted in this paper). If $n_{11}$ and/or $n_{12}$ are not unity (in absolute value), it has observable impact only on pass-band gain of transfer functions (LP, LPZ and BS). Note that this can be compensated by tuning of $B_{1}$ gain in opposite direction, therefore it represents no problem in practice.

Another non-ideality that should be taken into account is that current and voltage gains in the terminal relationships of the active elements may not be valid at high frequencies due to the non-idealities of active components. In order to observe impact of these non-idealities, $g_{\mathrm{m}}, B_{1}, B_{2}, n_{11}$ and $n_{12}$ were considered as frequency dependent, i.e. $g_{\mathrm{m}}(\boldsymbol{s}), B_{1}(\boldsymbol{s})$, $B_{2}(\boldsymbol{s}), n_{11}(\boldsymbol{s})$ and $n_{12}(\boldsymbol{s})$

$$
X(s)=\frac{x}{1+s \tau_{x}}
$$

where $x$ should be replaced by $g_{\mathrm{m}}, B_{1}, B_{2}, n_{11}$ and $n_{12}$ and $X(\boldsymbol{s})$ by $g_{\mathrm{m}}(\boldsymbol{s}), B_{1}(\boldsymbol{s}), B_{2}(\boldsymbol{s}), n_{11}(\boldsymbol{s})$ and $n_{12}(\boldsymbol{s})$. Further, $\tau_{\mathrm{x}}=$ $1 / \omega_{0}$, where $\omega_{0}$ stands for angular frequency forming the pole of the first-order function. A detailed analysis in Maple confirmed a well-known fact that in order to operate according to the theory up to frequency of, for instance, 10 $\mathrm{MHz}, f_{0}=\omega_{0} / 2 \pi$ should be at least $100 \mathrm{MHz}$ (10 times higher).

Relative sensitivities of the important parameters of this filter $\left(\omega_{\mathrm{p}}\right.$ and $\left.Q\right)$ on its parameters can be obtained by routine calculations from (6) and are low because none of them overcome \pm 0.5 .

\section{Simulation And Measurement Results}

A filter from Fig. 3 was prepared to be measured. DO-CA active element was implemented by part of the UCC-N1B circuit [39] (forming DO-CF part from Fig. 1(b)) and two current-mode multipliers EL2082 (forming two CA from Fig. 1(b)). VDCC active element was implemented by another UCC-N1B circuit consisting of one $\mathrm{CCII}+/$ (forming OTA part from Fig. 2(b)) and one UCC (Universal Current Conveyor), forming CCII part from Fig. 2(b). The filter parameters were: working capacitors $C_{1}=480 \mathrm{pF}, C_{2}=$ $240 \mathrm{pF}$, starting value of quality factor $Q=0.707$, theoretical pole frequency $f_{\mathrm{P}}=\{117 ; 313 ; 919\} \mathrm{kHz}$ obtained by $g_{\mathrm{m}}=G=1 / R=\{0.25 ; 0.67 ; 1.96\} \mathrm{mS}$.

Implementation of current amplifier by EL2082 circuit limits possible range of current gain $\left(B_{1}\right.$ or $\left.B_{2}\right)$ adjusting. As obvious from [40], current gain of EL2082 is adjusted by external DC voltage $\left(V_{\mathrm{G}}\right)$ and only $0 \leq V_{\mathrm{G}}<5 \mathrm{~V}$ is allowed. For range starting from 0 up to 2.5 , current gain is approximately equal to control voltage in its numerical value $\left(B \approx V_{\mathrm{G}}\right)$.

In order to suppress the expected impact of parasitic capacitances in nodes of the circuit on printed-circuit board (PCB), the values of working capacitors were decreased to $C_{1}=470 \mathrm{pF}, C_{2}=235 \mathrm{pF}$.

The results for pure LP configuration $\left(B_{1}=1, B_{2}=0\right)$ are depicted in Fig. 4 for three different pole frequencies. At frequencies above $10 \mathrm{MHz}$, the measured results are damaged by UCC-s features that have very limited operating bandwidth and are not designed to be operated at such high frequencies. However, the overall results are satisfactory in order to prove the concept. The results for pure HP configuration $\left(B_{1}=0, B_{2}=1\right)$ and pure BS configuration $\left(B_{1}\right.$ $\left.=1, B_{2}=1\right)$ are depicted in Fig. 5 and Fig. 6 respectively. Real measured pole frequencies are only slightly different than was expected from simulation in all three cases, as summarized in Table III

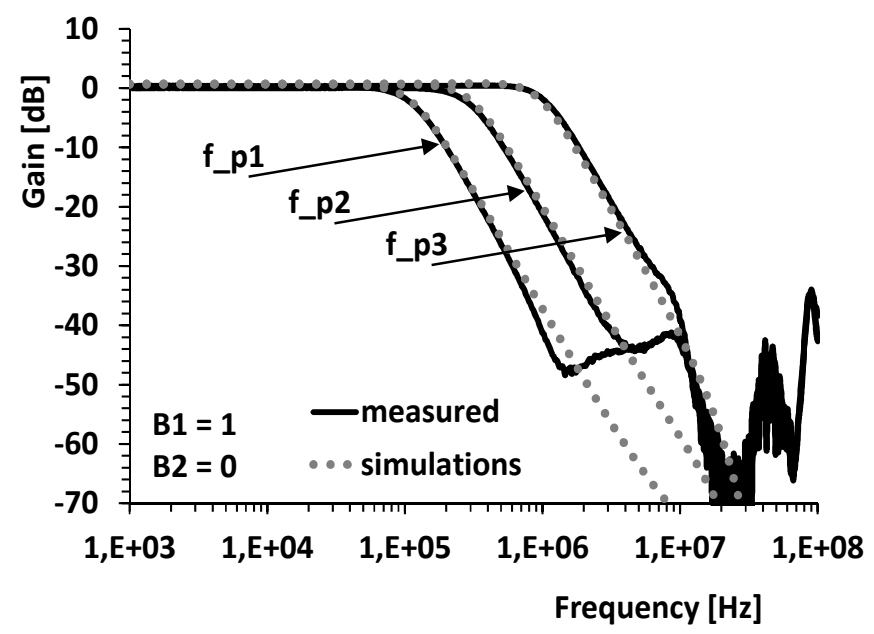

Fig. 4. Overall measurement results for LP response with unity pass-band gain while tuning pole frequency in comparison with simulations.

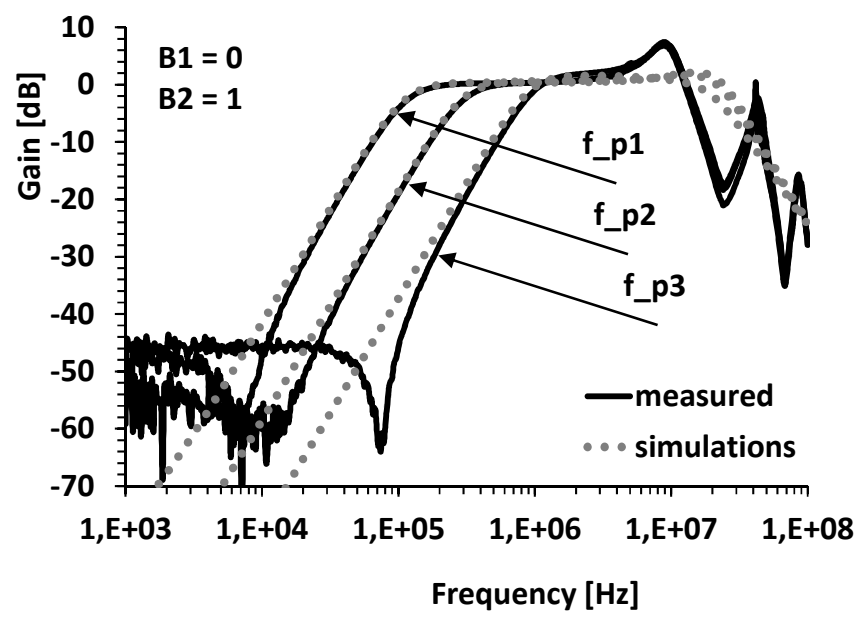

Fig. 5. Overall measurement results for HP response with unity pass-band gain while tuning pole frequency in comparison with simulations.

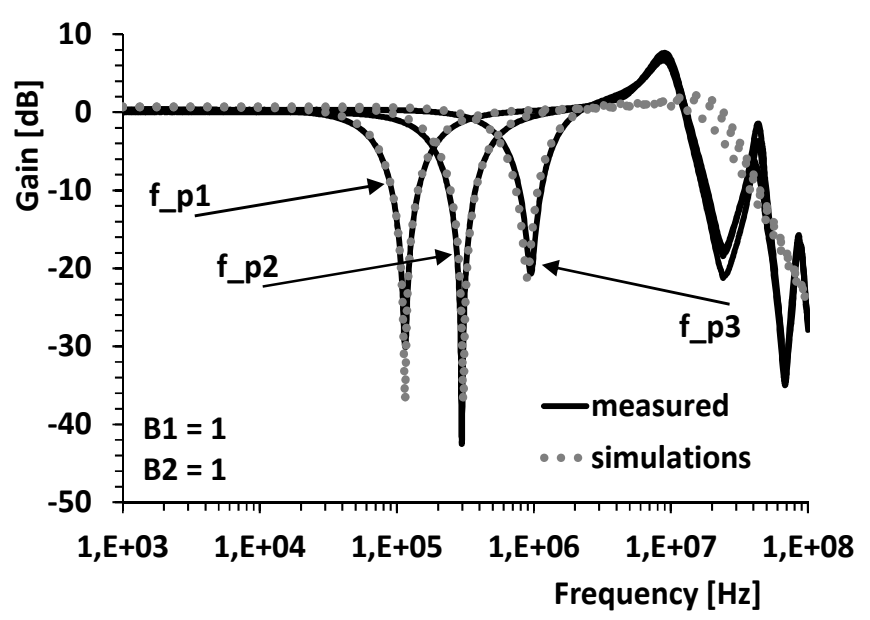

Fig. 6. Overall measurement results for BS response with unity pass-band gain while tuning pole frequency in comparison with simulations. 
Figure 7 and Fig. 8 provide the results for pass-band gain tuning in case of both LP and HP filters respectively. Passband gain is directly proportional to the $B$ gain as expected from (3) and obtained gains are summarized in Table IV.

TABLE III. COMPARISON OF OBTAINED VALUES IN THE CASE OF INDEPENDENT TUNING OF THE POLE FREQUENCY (FIG. 4, FIG. 5,

\begin{tabular}{|c|c|c|c|c|c|c|c|}
\hline \\
\hline 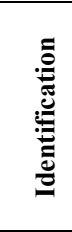 & 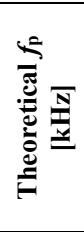 & 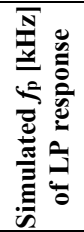 & 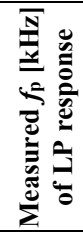 & 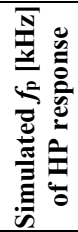 & 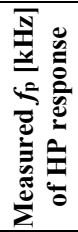 & 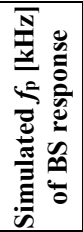 & 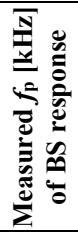 \\
\hline f p 1 & 117 & 113 & 113 & 114 & 114 & 117 & 115 \\
\hline $\mathrm{f}$ & 31 & 307 & 303 & 294 & 290 & 306 & 297 \\
\hline & 19 & 8 & & & & & \\
\hline
\end{tabular}

TABLE IV. COMPARISON OF OBTAINED VALUES IN THE CASE OF INDEPENDENT TUNING OF THE PASS-BAND GAIN (FIG. 7, FIG. 8).

\begin{tabular}{|c|c|c|c|c|c|}
\hline$\frac{\dot{\theta}}{\frac{1}{a}} \frac{T}{\dot{\theta}}$ & 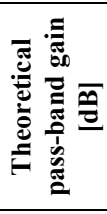 & 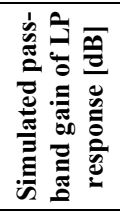 & 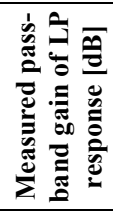 & 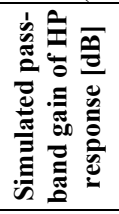 & 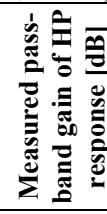 \\
\hline 0.1 & -20.0 & -18.9 & -19.2 & -19.0 & -18.9 \\
\hline 0.4 & -8.0 & -7.0 & -7.4 & -7.1 & -7.2 \\
\hline 1.0 & 0.0 & -0.7 & 0.3 & 0.6 & 0.5 \\
\hline 2.5 & 8.0 & 8.0 & 8.1 & 7.9 & 8.1 \\
\hline
\end{tabular}

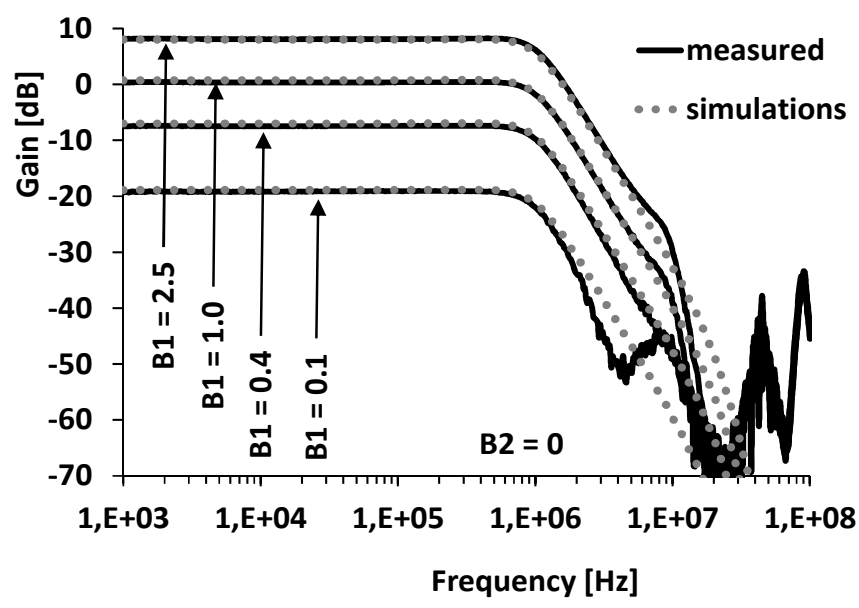

Fig. 7. Overall measurement results for $\mathrm{LP}$ response with $f_{\mathrm{P}}$ THEOR $=$ $919 \mathrm{kHz}$ and while tuning pass-band gain by $B_{1}$ in comparison with simulations.

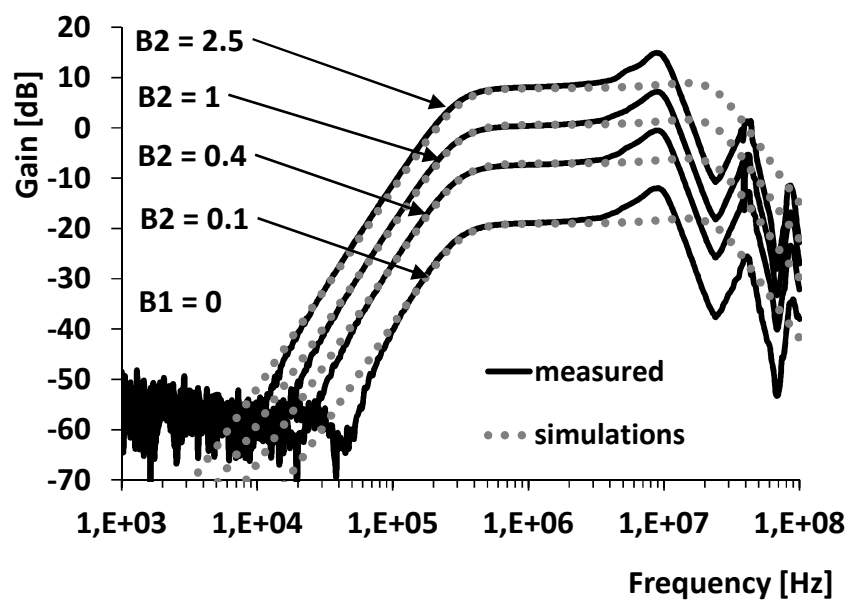

Fig. 8. Overall measurement results for $\mathrm{HP}$ response with $f_{\mathrm{P}}$ THEOR $=$ $313 \mathrm{kHz}$ and while tuning pass-band gain by $B_{2}$ in comparison with simulations.
Figure 9 and Fig. 10 include the measured characteristics for stop-band gain tuning.

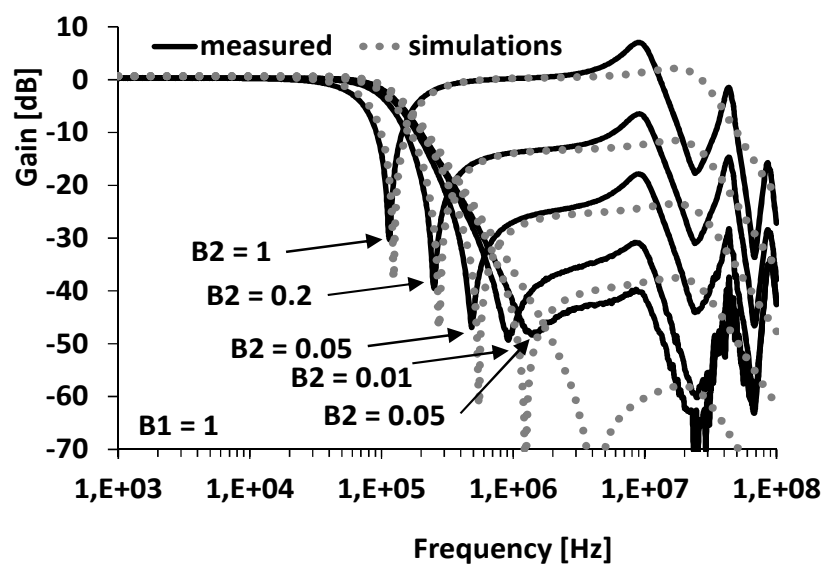

Fig. 9. Overall measurement results for LPZ response with $f_{\mathrm{P}_{-} \mathrm{THEOR}}=$ $117 \mathrm{kHz}$ with unity pass-band gain while tuning stop-band gain (attenuation) by $B_{2}$ in comparison with simulations.

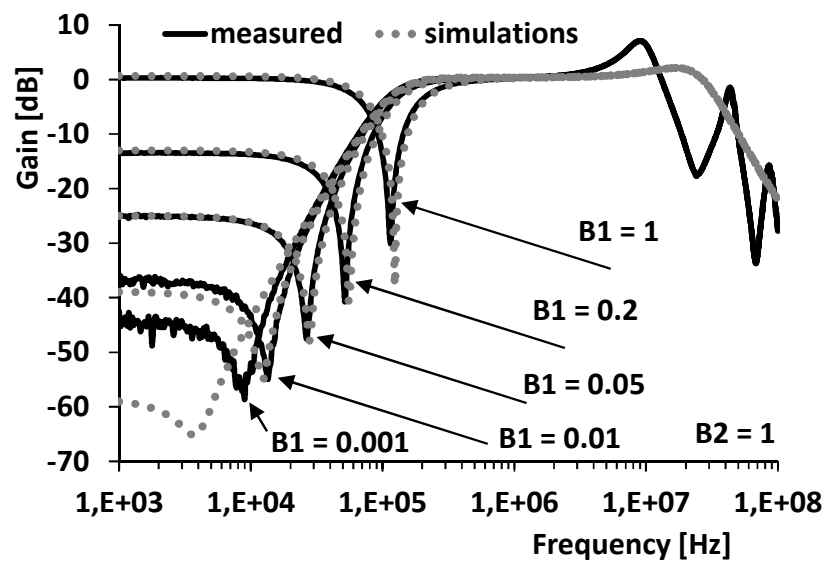

Fig. 10. Overall measurement results for $\mathrm{HPZ}$ response $\left(f_{\mathrm{P}}=117 \mathrm{kHz}\right)$ with unity pass-band gain while tuning stop-band gain (attenuation) by $B_{1}$ in comparison with simulations.

It is obvious from the graphs that when $B$ is tuned from 0 to 1 ( $B_{2}$ in case of LP and $B_{1}$ in case of HP), stop-band attenuation decreases (gain grows) and when $B_{1}=B_{2}=1$, both functions change into BS. If $B=0.001$ ( $B_{2}$ in case of LP and $B_{1}$ in case of HP), stop-band gain should be theoretically $-60 \mathrm{~dB}\left(K=20 \cdot \log _{10} 0.001=-60 \mathrm{~dB}\right)$, however it is not possible to achieve because real implementation of filter on PCB using the above mentioned active elements is limited by $-50 \mathrm{~dB}$.

\section{CONCLUSIONS}

The designed reconnection-less reconfigurable filter providing LP, HP, LPZ, HPZ and BS transfer function without any change or switching in the topology was presented. Its measured features are influenced by real parameters of the active elements that were used. Also real PCB and its design has direct impact on the measured characteristics. In our case, the highest attenuation was limited to $50 \mathrm{~dB}$ and the results are in good agreement with theory up to frequency of $10 \mathrm{MHz}$, tuning range was from $115 \mathrm{kHz}$ to $959 \mathrm{kHz}$ (in case of BS response). Nevertheless, we consider these results as very good. Of course, the test with real devices (UCC and EL2082) could be substituted or supplemented by the simulations with CMOS transistor 
structures. Behavioural modelling (as it was used and presented in this paper) is a very useful way how to verify the design. If the filter prepared with help of universal active elements, employed as a part of the behavioural model, works well, possible non-universal transistor structure would have much better features.

\section{REFERENCES}

[1] W. K. Chen, The Circuits and Filters Handbook, Third Edition. CRC Press: New York, 2009.

[2] M. Kumngern, F. Khateb, K. Dejhan, P. Phasukkit, S. Tungjitkusolmun, "Voltage-mode multifunction biquadratic filters using new ultra-low-power differential difference current conveyors", Radioengineering, vol. 22, no. 2, pp. 448-457, 2013.

[3] F. Kacar, B. Metin, H. Kuntman, O. Cicekoglu, "Current-mode multifunction filters using a single FDCCII", in Proc. Int. Conf. on Electrical and Electronics Engineering (ELECO), Bursa, 2009, pp. $54-57$.

[4] H. Y. Wang, C. T. Lee, "Versatile insensitive current-mode universal biquad implementation using current conveyors", IEEE Trans. Circuits and Systems II: Analog and Digital Signal Processing, vol. 48, no. 4, pp. 409-413, 2001. [Online]. Available: http://dx.doi.org/10.1109/82.933806

[5] Y. Sun, J. K. Fidler, "Structure generation of current-mode two integrator loop dual output-OTA grounded capacitor filters", IEEE Trans. Circuits and Systems II: Analog and Digital Signal Proc., vol. 43, no. 9, pp. 659-663, 1996. [Online]. Available: http://dx.doi.org/10.1109/82.536762

[6] E. Yuce, "Voltage-mode multifunction filters employing a single dvcc and grounded capacitors", IEEE Trans. Instrumentation and Measurement, vol. 58, no. 7, pp. 2216-2221, 2009. [Online]. Available: http://dx.doi.org/10.1109/TIM.2009.2013671

[7] B. N. Ray, "Synthesis of programmable multi-input current-mode linear analog circuits", IEEE Trans. Circuits and Systems I: Regular papers, vol. 51, no. 8, pp. 1440-1456, 2004. [Online]. Available: http://dx.doi.org/10.1109/TCSI.2004.832713

[8] J. Jerabek, K. Vrba, "SIMO type low-input and high-output impedance current- mode universal filter employing three universal current conveyors", Int. Journal of Electronics and Communications, vol. 64, no. 6, pp. 588-593, 2010. [Online]. Available: http://dx.doi.org/10.1016/j.aeue.2009.03.002

[9] S. Minaei, E. Yuce, O. Cicekoglu, "Electronically tunable multi-input single-output voltage-mode filter", in Proc. European Conf. Circuits Theory and Design, (ECCTD 2005), pp. 401-403. [Online]. Available: http://dx.doi.org/10.1109/ECCTD.2005.1523145

[10] C. H. Chang, H. S. Wu, J. Yang, C. K. C. Tzuangh, "Coalesced single-input single-output dual-band filter", in Proc. IEEE MTT-S Microwave Symposium Digest, Philadelphia, 2003, pp. 511-514. [Online]. Available: http://dx.doi.org/10.1109/MWSYM. 2003.1210988

[11] I. A. Khan, M. I. Masud, S. A. Moiz, "Reconfigurable fully differential first order all pass filter using digitally controlled CMOS DVCC", in Proc. 8th IEEE GCC Conf. and Exhibition, Muscat, 2015, pp. 1-5. [Online]. Available: http://dx.doi.org/10.1109/ IEEEGCC.2015.7060082

[12] Z. P. Wang, J. Kelly, P. S. Hall, "Reconfigurable bandstop filter with wide tuning range", Electronic Letters, vol. 46, no. 11, pp. 771-772, 2010. [Online]. Available: $h$ ttp://dx.doi.org/10.1049/el.2010.0886

[13] E. J. Naglich, J. Lee, D. Peroulis, W. J. Chappel, "Switchless tunable bandstop-to-all-pass reconfigurable filter", in IEEE Trans. Microwave Theory and Techniques, vol. 60, no. 5, pp. 1258-1265, 2012. [Online]. Available: http://dx.doi.org/10.1109/ TMTT.2012.2188723

[14] B. A. Adoum, W. P. Wen, "Investigation of band-stop to all pass reconfigurable filter", in Proc. 4th Int. Conf. on Intelligent and Advanced Systems (ICIAS 2012), Kuala Lumpur, 2012, pp. 190-193. [Online]. Available: http://dx.doi.org/10.1109/ICIAS.2012.6306185

[15] D. Biolek, R. Senani, V. Biolkova, Z. Kolka, "Active elements for analog signal processing: classification, review and new proposals", Radioengineering, vol. 17 , no. 4, pp. 15-32, 2008.

[16] H. Alzaher, O. Alees, N. Tasadduq, "Programmable multi-gain current amplifier", IET Circuits, Devices \& Systems, vol. 6, no. 6, pp. 421-428, 2012. [Online]. Available: http://dx.doi.org/10.1049/ iet-cds.2012.0086

[17] J. Jerabek, J. Koton, R. Sotner, K. Vrba, “Adjustable band-pass filter with current active elements: two fully-differential and single- ended solutions", Analog Integrated Circuits and Signal Processing, vol. 74, no. 1, pp. 129-139, 2013. [Online]. Available: http://dx.doi.org/10.1007/s10470-012-9942-4

[18] R. L. Geiger, E. Sanchez-Sinencio, "Active filter design using operational transconductance amplifiers: a tutorial", IEEE Circuits and Devices Magazine, vol. 1, no. 2, pp. 20-32, 1985. [Online] Available: http://dx.doi.org/10.1109/MCD.1985.6311946

[19] A. Fabre, O. Saaid, F. Wiest, C. Boucheron, "High frequency applications based on a new current controlled conveyor", IEEE TCAS - I: Fundamental Theory and Applications, vol. 43, no. 2, pp. 82-91, 1996. [Online]. Available: http://dx.doi.org/10.1109/ 81.486430

[20] A. U. Keskin, D. Biolek, E. Hancioglu, V. Biolkova, "Current-mode KHN filter employing Current Differencing Transconductance Amplifiers", AEU - Int. Journal of Electronics and Communications, vol. 60, no. 6, pp. 443-446, 2006. [Online]. Available: http://dx.doi.org/10.1016/j.aeue.2005.09.003

[21] W. Jaikla, A. Lahiri, "Resistor-less current-mode four-phase quadrature oscillator using CCCDTAs and grounded capacitors", AEU - Int. Journal of Electronics and Communications, vol. 66, no. 3, pp. 214-218, 2011. [Online]. Available: http://dx.doi.org/ 10.1016/j.aeue.2011.07.001

[22] C. Sakul, W. Jaikla, K. Dejhan, "New resistorless current-mode Quadrature Oscillators Using 2 CCCDTAs and Grounded Capacitors", Radioengineering, vol. 20, no. 4, pp. 890-896, 2011.

[23] R. Prokop, V. Musil, "Modular approach to design of modern circuit blocks for current signal processing and new device CCTA", in Proc. Seventh IASTED Int. Conf. on Signal and Image Proc., Anaheim, 2005, pp. 494-499.

[24] M. Siripruchyanun, W. Jaikla, "Current controlled current conveyor transconductance amplifier (CCCCTA): a building block for analog signal processing", Electrical Engineering, vol. 90, no. 6, pp. 443453, 2008. [Online]. Available: http://dx.doi.org/10.1007/s00202007-0095-x

[25] D. Biolek, A. Lahiri, W. Jaikla, M. Siripruchyanun, J. Bajer, "Realisation of electronically tunable voltage-mode/current-mode quadrature sinusoidal oscillator using ZC-CG-CDBA", Microelectronics Journal, vol. 42, no. 10, pp. 1116-1123, 2011 . [Online]. Available: http://dx.doi.org/10.1016/j.mejo.2011.07.004

[26] G. Soulitis, C. Psychalinos, "Electronically controlled multiphase sinusoidal oscillators using current amplifiers", Int $J$ of Circuit Theory and Applications, vol. 37, pp. 43-52, 2008. [Online]. Available: http://dx.doi.org/10.1002/cta.486

[27] D. Prasad, J. Ahmad, "New electronically-controllable lossless synthetic floating inductance circuit using single VDCC", Circuits and Systems, vol. 5, pp. 13-17, 2014. [Online]. Available: http://dx.doi.org/10.4236/cs.2014.51003

[28] F. Kacar, A. Yesil, "Positive/negative lossy/lossless grounded inductance simulators employing single VDCC and only two passive elements", AEU - Int. Journal of Electronics and Communications, vol. 68, no. 1, pp. 73-78, 2014. [Online]. Available: http://dx.doi.org/10.1016/j.aeue.2013.08.020

[29] J. Jerabek, R. Sotner, K. Vrba, "TISO adjustable filter with controllable controlled-gain voltage differencing current conveyor", Journal of Electrical Engineering, vol. 65, no. 3, pp. 137-143, 2014. [Online]. Available: http://dx.doi.org/10.2478/jee-2014-002

[30] R. Sotner, N. Herencsar, J. Jerabek, R. Prokop, A. Kartci, T. Dostal, K. Vrba, "Z-Copy controlled-gain voltage differencing current conveyor: advanced possibilities in direct electronic control of firstorder filter", Elektronika Ir Elektrotechnika, vol. 20, no. 6, pp. 7783, 2014. [Online]. Available: http://dx.doi.org/10.5755 /j01.eee.20.6.7272

[31] R. Sotner, J. Jerabek, N. Herencsar, R. Prokop, K. Vrba, T. Dostal "Resistor-less first-order filter design with electronical reconfiguration of its transfer function", in Proc. 24th Int. Conf. Radioelektronika, Bratislava, 2014, pp. 63-66. [Online]. Available: http://dx.doi.org/10.1109/Radioelek.2014.6828417

[32] J. Petrzela, R. Sotner, "Systematic design procedure towards reconfigurable first- order filters", in Proc. 24th Int. Conf. Radioelektronika, Bratislava, 2014, pp. 1-4. [Online]. Available: http://dx.doi.org/10.1109/Radioelek.2014.6828462

[33] R. Sotner, J. Jerabek, N. Herencsar, T. Zak, W. Jaikla, K. Vrba, "Modified current differencing unit and its application for electronically reconfigurable simple first-order transfer function", Advances in Electrical and Computer Engineering, vol. 15, no. 1, pp. 3-10, 2015. [Online]. Available: http://dx.doi.org/10.4316/ AECE.2015.01001 
[34] R. Sotner, J. Jerabek, N. Herencsar, R. Prokop, K. Vrba, T. Dostal, "First-order reconfigurable reconnection-less filters using modified current differencing unit", in Proc. 25th Int. Conf. Radioelektronika Pardubice, 2015, pp. 46-50. [Online]. Available: http://dx.doi.org/ 10.4316/10.1109/ RADIOELEK.2015.7128992

[35] R. Sotner, J. Jerabek, B. Sevcik, T. Dostal, K. Vrba, "Novel Solution of Notch/All-pass Filter with Special Electronic Adjusting of Attenuation in the Stop Band", Elektronika Ir Elektrotechnika, vol. 17, no. 7, pp. 37-42, 2011. [Online]. Available: http://dx.doi.org/ $10.4316 / 10.5755 /$ j01.eee.113.7.609

[36] R. Sotner, J. Jerabek, J. Petrzela, K. Vrba, T. Dostal, "Design of fully adjustable solution of band-reject/all- pass filter transfer function using signal flow graph approach", in Proc. 24th Int. Conf. Radioelektronika, Bratislava, 2014, pp. 67-70. [Online]. Available: http://dx.doi.org/10.4316/10.1109/Radioelek.2014.6828418
[37] R. Sotner, J. Jerabek, J. Petrzela, K. Vrba, T. Dostal, "Solutions of Reconnection-less OTA-based Biquads with Electronical Transfer Response Reconfiguration", in Proc. 25th Int. Conf. Radioelektronika, Pardubice, 2015, pp. 40-45. [Online]. Available: http://dx.doi.org/10.4316/10.1109/RADIOELEK.2015.7128991

[38] R. Sotner, J. Petrzela, J. Jerabek, T. Dostal, "Reconnection-less OTAbased biquad filter with electronically reconfigurable transfers", Elektronika Ir Elektrotechnika, vol. 21, no. 3, pp. 33-37, 2015. [Online]. Available: http://dx.doi.org/10.5755/j01.eee.21.3.10205

[39] J. Cajka, K. Vrba, J. Misurec, "New universal biquad using UCCX devices", Frequenz, vol. 60, no. 7-8, pp. 138-141, 2006. [Online]. Available: http://dx.doi.org/10.1515/FREQ.2006.60.7-8.138

[40] Intersil, "EL2082 chip (datasheet), 1996. [Online]. Available: http://www.intersil.com/content/dam/Intersil/documents/el20/el2082. pdf 